\title{
Deseo y rechazo como dinámica poscolonial en la novela "compasión absoluta" de Carol Zardetto
}

\author{
Ivannia Barboza Leitón*
}

\section{RESUMEN}

Este artículo explora desde la protagonista la dinámica del deseo y el rechazo como contradicciones experimentadas en las sociedades poscoloniales, tanto para el sujeto que domina como para el sujeto-objeto que es dominado. Irene, la protagonista, integra múltiples visiones que entretejen su identidad a la par que se reelabora la historia de Guatemala en las narraciones orales familiares. ¿Por qué se desean sujetos-objetos, espacios geográficos, vivencias personales, y al mismo tiempo rechazan? ¿Cómo se constituye la identidad de la protagonista con esa dualidad tan fluctuante? ¿Por qué ese afán de rememorar su patria Guatemala con los relatos de la abuela y con sus propias evocaciones? $\mathrm{Y}$, finalmente, ¿por qué esa inquietante comparación entre un pasado que se borra al mismo tiempo que recrea "un presente" y un posible futuro con otros y desde otros espacios ajenos al círculo familiar? Son interrogantes que llevan al objetivo propuesto en el trabajo.

Ese fluir temporal será estudiado desde una visión dialéctica que permite reconocer a Guatemala como la periferia, frente a otros lugares como el centro, el espacio que satisface los sentidos de la protagonista.

Palabras clave: novela centroamericana, Modernidad, poscolonialismo, patriarcalismo, identidad, subjetividad.

\begin{abstract}
This article from the protagonist explores the dynamics of desire and rejection experienced as contradictions in postcolonial societies, both for the subject that dominates to the subject-object is dominated. Irene, the protagonist integrates multiple visions that weave their identity at the same time it reworks the history of Guatemala in the family oral histories.

Why you want to subject-objects, geographical areas, personal experiences, and yet refuse? How is the identity of the protagonist with this duality as changing? Why this desire to remember their homeland Guatemala with stories of his grandmother and her own recollections? And finally, why this disturbing comparison between a past that is erased while recreating a "present" and a possible future with each other and from other spaces outside the family circle? These are questions that lead to the goal of this paper. The temporal flow will be studied from a dialectical view which enables us to Guatemala and the periphery, compared to other places like downtown, the space that satisfies the senses of the protagonist.
\end{abstract}

Key words: Central American novel, modernity, post-colonialism, patriarchy, identity and subjectivity.

Profesora de Estudios Generales de la UCR. Máster en Literatura Latinoamericana. Egresada del Doctorado en Estudios de la Sociedad y la Cultura. UCR.

Revista ESPICA Año X, N. 21: 23-45, Enero-Junio 2011 
"La rueda del tiempo no espera. Como un molino que tritura granos, el tiempo tritura ... mundos". ConPasión Absoluta, Carol Zardetto.

\section{Introducción}

ConPasión Absoluta de Carol Zardetto $^{1}$ explora, a través de su personaje principal, Irene, un viaje de regreso a la patria y a sus orígenes. En un abigarrado y complejo proceso de escritura entre la evocación, la oralidad y la tan pospuesta actividad de escritura, Irene trata de mostrar cómo su frágil círculo familiar (con clara presencia femenina y con esporádicas inclusiones masculinas) se rompe con la muerte de la abuela, personaje emblemático, quien al fin y al cabo hace que Irene regrese a Guatemala. Entre los anacronismos, las rupturas temporales y el fluir de la conciencia se reconoce que la protagonista está agobiada por una ruptura amorosa con Costa, aludido constantemente con la inicial del nombre y por la búsqueda de independencia (tanto emocional como económica) en una patria que ya no siente como suya. La obra integra, además, múltiples memorias individuales subordinadas por el sistema oficial que las colectiviza, aunque éstas pugnen por mostrar los procesos político-militares de la nación centroamericana.

La obra le valió a la autora convertirse en la primera mujer guatemalteca en obtener el Premio Centroamericano de Novela "Mario Monteforte Toledo"” en el año 2004.

El objetivo del presente ensayo consiste en analizar cómo se constituyen el deseo y el rechazo hacia el sujeto subordinado en la dinámica poscolonial desde la obra ConPasión Absoluta de Carol Zardetto. El análisis no quedaría completo sin la inclusión del estudio de género que como sistema de dominación ha marcado hondamente las sociedades, en este caso la guatemalteca porque: "El análisis postcolonial del atravesamiento del sujeto por variables como el sexo, la etnia, la clase, la religión, la opción sexual u otras, inevitablemente socava las fronteras identitarias reguladas por las narrativas dominantes" (Femenías, 2005: 159).

Aunado a lo anterior, se estudiará la identidad de la protagonista a través de visiones que fluyen en un constante ir y venir del pasado-presente en Guatemala (la periferia), en contraste también con un pasado-presente en Canadá (el centro). ConPasión Absoluta permite explorar, además, una crisis

\footnotetext{
1. Guatemala.

2. El premio fue instituido por la Fundación Mario Monteforte Toledo, en Guatemala en el año 1997. Se premian las ramas de la narrativa, específicamente, novela y cuento.
} 
de sentido que se integra en Irene y que entreteje el mundo externo (ciudad, historia, convivencia social) en contraste con los espacios más íntimos (el yo, la subjetividad, la identidad, la búsqueda de sentido) y la integración o sumas de todos los anteriores elementos en el complejo sistema social dominado por el patriarcado -elemento de dominio arraigado en la poscolonialidad-.

Para lo anterior, estructuro el análisis desde los ejes espacio-temporales porque configuran el accionar de Irene y son indicadores de un fluir del pensamiento, combinando unas relaciones deícticas, así como: "la lógica del dominio $^{3}$ entendida a partir de la dialéctica binaria Uno-Otro, en términos de colonizador-colonizado, y (que) se mueve críticamente dentro de un marco moderno de poder" (Femenías, 2005: 159).

Con el análisis pretendo reconocer que Irene es un sujeto fragmentado, desdibujado, limítrofe entre una Modernidad inacabada y una poscolonialidad que desea, que le atrae. El abordaje exige una división interna en dos apartados, cada uno de ellos con un subtítulo que sintetiza la relación por estudiar; asimismo, al final presento unas conclusiones parciales que cierran los análisis.

\section{Un pasado-presente anclado en la colonialidad}

En este apartado analizo la inserción de la protagonista en el espacio familiar, en su patria, y en un pasado que subyace en los relatos de la abuela, respectivamente.

El primer acontecimiento que logra insertar a Irene al hogar, de vuelta, es la noticia de que su abuela Victoria está en trance de muerte. Este hecho da pie para analizar las relaciones familiares, el círculo que se reconoce distante pues los vínculos madre-hija no indican compenetración afectiva. Irene -personaje principal y voz preponderante en la narración y articuladora de otras voces femeninas de su familiamanifiesta: "Allí vive mi madre con su otra familia" (Zardetto, 2005: 21)4.

La relación entre ambas mujeres no es buena. Irene, en realidad, con quien siente afinidad y a quien asume como madre (por la conexión establecida con ella) es con su abuela, como señala Jessica Benjamín (1997) hay entonces un "relacionamiento intersubjetivo". Irene le achaca a su madre Nena dos acciones que friccionaron su ya deteriorada relación: el matrimonio con don Asunción y la orden de que Irene se casara por apariencia:

\footnotetext{
3. A lo largo del trabajo se respeta el uso de la cursiva empleada en los textos originales.

4. Se consigna el número de página de la edición indicada en la bibliografía.
} 
Vestida de blanco, como quería mi madre, quien me agradeció oficialmente años después esa condescendencia. Salir vestida de blanco, cumplir con tanta hipocresía. Quería cumplir... Me río de mí misma: la suerte me acompañó: sufría un desengaño. El matrimonio podía ser un conjunto vacio, un espacio lleno de nada (21).

Para Irene resulta irónico y predecible el fracaso de su relación de pareja. Entre reconocer el enlace de Nena con don Asunción como una irrupción a la armonía familiar, y luego experimentar por sí misma el vacío de una relación amorosa frustrante, subyace el deseo de complacencia de la madre. Mabel Burín indica que las fricciones entre madre e hija representan un campo ideal para la "ideología patriarcal (que) posiciona a las mujeres como sujetos dentro de las prácticas sociales de la maternidad y, por extensión, normativiza los deseos femeninos alrededor del deseo maternal" (Burín, 1992: 216). Irene cumple, porque así como ha sucedido durante milenios, la madre le dirá a la hija que su papel en la sociedad consiste en casarse y tener hijos.

Por lo anterior, Irene obedeció el mandato materno aunque esto le acarreara amargura y ahora, como una rebelde que cede sólo ante la enfermedad de su abuela, hace su ingreso al círculo familiar: "Me resisto a esta casa, ajena sin la presencia de mi madre. Si no fuera por la gravedad de la abuela, no estaría aquí" (23).

La obra ConPasión Absoluta contempla personajes femeninos con autonomía e independencia que han sido producto de luchas a lo interno de la nación, de los espacios de dominación masculina y de imposiciones sociales. Incluso explora un ámbito que ocasionalmente abre su entorno para dejar pasar a una figura masculina y que ésta se mantenga ahí. Las irrupciones son escasas, pero marcan a las mujeres del relato.

Por ejemplo, se reconocen las experiencias de la abuela como maestra de escuela, al igual que la autonomía económica y social que representó el salón de belleza para la madre de Irene, donde trabajan también sus hermanas. La posesión de un salón de belleza en la misma casa representa la unión estratégica de los ámbitos privados y públicos; es un manejo doble, así como doble es la atención de la casa y del salón. Socialmente no se descuida el hogar y se obtiene dinero. El ajetreo del salón es motivo de recuerdo para Irene: "Ella y mis tías cortaban el pelo, hacían manicure y permanentes con una máquina eléctrica que conectaban a las señoras" (15).

Las tías Ibis y Aura o las Violetas instauran en el círculo familiar una renovada visión de relacionarse con el sexo opuesto, diferentes en circunstancias, prácticas e ideas a las mujeres mayores de la familia: 
Por aquellos tiempos, mis tías eran adolescentes. Rondaban el salón los muchachos del barrio, tratando de enamorarlas. Para facilitarlo, ellas se paraban en la puerta - a ver pasar gente, decian-con sus jóvenes cuerpos sudando la lentitud y el calor de la tarde (16-17).

Las jóvenes, disímiles totalmente en sus personalidades, fueron modelos por seguir para Irene, quien vio en ellas autonomía, estilo y personalidad. La tía Ibis era "Mentirosa y exagerada, tenía el pelo pintado de rojo, usaba vestidos ceñidos y fumaba" (17), mientras que la tía Aura o las Violetas era "Callada y taciturna, de figura finita y envuelta en su larga melena negra, parecía siempre un poco ausente... como si nada pudiera tocarla" (17).

Dos acontecimientos marcan la ruptura de ese paraíso para Irene; primero, la ida de la tía Ibis, y luego el matrimonio de su madre con don Asunción: "Ibis fue la primera en irse. Un convertible rojo trajo a un mulato de apellido francés frente a la casa una tarde" (33). En ambos casos, la llegada de un hombre rompe con la unidad familiar, con esa sensación de comodidad y de sentirse fortalecida en el círculo femenino.

Sin embargo, más abruptamente resulta la salida de la tía Ibis quien soltera queda embarazada del mulato de apellido francés que desaparece. Al respecto indica Pierre Bourdieu que las mujeres al término de su uso en el plano productivo laboral, sexual o de explotación pasan a ser meros objetos que merman su valor en una sociedad de intercambio, de consumo; por lo anterior, la tía es ahora "menos valiosa", "menos casadera" que anteriormente, porque su imagen se basa en "la estructura de un mercado de los bienes simbólicos cuya ley fundamental es que las mujeres son tratadas allí como unos objetos que circulan de abajo hacia arriba" (Bourdieu, 2000: 59).

La abuela Victoria obliga a los "transgresores" a casarse para cuidar una imagen, es la misma situación vivida por la anciana y que como eslabón de una cadena se reproduce de generación en generación. A lo anterior, hay que sumarle que el origen de la familia de Irene es indígena por lo que la abuela Victoria, así como lo hizo la madre de ella, reclama un "honor", "una imagen" que ha sido manchada. Y aunque no haya hombres en la familia, ellas para sí mismas reclaman una imagen, frente a otras mujeres, incluso indígenas, en Guatemala, donde lamentablemente, no tienen nada que perder en el mercado del dominio patriarcal.

Lo sucedido a la tía Ibis engarza ya otras historias en la familia: la abuela Victoria fue violada a los 14 años, su madre pide ante el hombre el matrimonio para su hija. Posteriormente, la historia se repite con Nena, madre de Irene. La historia es circular: Nena engendra a Irene con un hombre 
que no se casó con ella, por eso Irene recuerda que su padre trata de llenar la ausencia con costosas muñecas, objetos con los cuales no se puede jugar pues resultan desproporcionados para la niña, además de que son ejemplo de una fría y distante mediación entre ella y el progenitor ausente:

Era regalo de mi padre, como otros que llegaban siempre en las navidades (...) Cajas enormes con muñecas gigantes. No podia jugar con ellas debido a su desmesura y quedaban abandonadas como estáticas presencias que con los años fueron poblando los roperos (18).

La ausencia del padre en la familia de la protagonista no es motivo de desdicha; por el contrario, ella vive feliz en su mundo hasta que hace su llegada don Asunción; con la aparición del "nuevo padre" se rompe la armonía: "y existe algo de paradójico en que ese día, cerca de Navidad, mi salvador fuese Don Asunción, quien habría de hacer añicos el tenue cristal que resguardaba mi infancia" (22).

La idea del matrimonio no era primordial en la vida de Irene hasta que efectivamente se concretan los lazos entre Nena y don Asunción, por lo cual, ahora Irene tiene dos razones para casarse: primero, el matrimonio de su madre y la exigencia e imposición de ésta, como segundo motivo.

La vuelta de Irene, tanto al espacio familiar como a la patria, no ha sido agradable y rápida como ella lo esperaba. Llegar a Guatemala poscolonial es llegar a un pasado que no vivió, pero que llega a formar parte de ella desde los relatos de su abuela. En las narraciones de la abuela Victoria confluyen las voces del resto de las mujeres de la familia. Al decir de Gayatri Spivak y enlazando con el círculo familiar femenino de la protagonista se manifiesta: “(que) la mujer subalterna continuará siendo tan muda como siempre" (Spivak, s.a.: 43). Yo rescato que la actividad de "hablar entre subalternos" es valiosa porque aunque se dé en un mismo nivel de inferioridad, la palabra está viva como símbolo de liberación entre pares.

Por ello, la abuela Victoria es la voz subalterna que está a punto de extinguirse y que como tradición femenina de la oralidad -elemento desvalorizado en las sociedades colonialistas occidentales- transmite su conocimiento a la nieta. Son ecos que traen al presente una Guatemala anclada en el pasado, en la poscolonialidad y el dominio:

El Gobierno inició la construcción de caminos y muelles en la costa del Pacífico. El floreciente comercio exterior, exigía las condiciones adecuadas: puertos, ferrocarriles, telégrafos, bancos... el futuro llegaba. Ya lo decían los ecos que venían de Francia, habia que ser moderno, absolutamente moderno (63).

Por lo anterior, en los espacios geográficos, en los sistemas de 
producción y en los productores de capital económico operaba la idea de lo novedoso como todo aquello que provenía de otras tierras. Anthony Giddens indica que efectivamente, aunque las relaciones se instauren en la modernidad, la ausencia de esos lazos es visible, pero no inexistente:

El advenimiento de la modernidad paulatinamente separa el espacio del lugar al fomentar las relaciones entre los "ausentes" localizados a distancia de cualquier situación de interacción cara-a-cara. En las condiciones de la modernidad, el lugar se hace crecientemente fantasmagórico, es decir, los aspectos locales son penetrados en profundidad $y$ configurados por influencias sociales que se generan a gran distancia de ellos (Giddens, 1993: 30).

Es imperioso el llamado que debe atender la sociedad guatemalteca frente a la brecha que le tiende la potencia extranjera, a una modernidad que impulsará, asimismo, el rompimiento de los tejidos sociales que hacen posible, al menos, una convivencia armoniosa. Dicha modernidad -legitimadora del sistema de poder dominante- que podría pensarse eminentemente industrial, no deja de lado el aspecto humano tocado también por las ideas del orden, la racionalidad y el progreso.
El colonizador desde que descubrió el sujeto-objeto de sus deseos afianzó con la violación una estrategia, incluso subconsciente, subrayada por Hernán Darío Correa como un ejercicio binario:

No es dificil descubrir en todas esas acciones que sus gestores tienen miedo; como tampoco es difícil reconocer en ellas un intenso deseo y deforme deseo por la mujer, el goce juvenil, el niño y la palabra. Con ellas se evidencia que a sus agentes les aterra el Otro; pero también que lo necesitan (Correa, 1987: 19).

El hijo criollo del patrón, el futuro nuevo hacendado, que contará con nuevas y modernas máquinas para efectuar su trabajo, inicia el detenimiento del eje historia-tiempo violentando a Victoria. Con el abuso sexual de Victoria a los 14 años por Manuel, hijo de don Onofre de la Rosa y Morel, inmigrante español, terrateniente sumamente adinerado, también se instauró otra poscolonialidad: "Habló, sin embargo, de su inicial estupor frente a la presencia del hombre en su cuerpo, habló de ese olor penetrante, de esa sensación de sentirse abierta y descoyuntada" (60). El proceso de dominación ahora no es solo territorial, es también de cuerpos y poblaciones como lo fue en la etapa colonial ${ }^{5}$.

5. Cfr. Aníbal Quijano. "Colonialidad del poder, eurocentrismo y América Latina”, específicamente el apartado "El eurocentrismo y la cuestión nacional: El Estado-nación". 
La abuela Victoria es la alegoría de la nación guatemalteca violentada, usurpada, utilizada como mercancía, en este caso particular, como objeto para la satisfacción de los placeres. La nación ultrajada, al igual que las mujeres, han sido los espaciossujetos con los que han contado los hombres civilizadores, los varones blancos y adinerados para erigir sus estandartes del progreso y el adelanto. Las tierras y lo que estas ofrezcan para generar ganancias, al igual que las mujeres, son símbolos de explotación y colonialidad:

Ese nuevo y radical dualismo no afectó solamente a las relaciones raciales de dominación, sino también a las más antiguas, las relaciones sexuales de dominación. En adelante, el lugar de las mujeres, muy en especial el de las mujeres de las razas inferiores, quedó estereotipado junto con el resto de los cuerpos, y tanto más inferiores fueran sus razas, tanto más cerca de la naturaleza... (Quijano, 2000: 225).

El dominio persiste en el siglo XX a través de la imagen de dominio español en la tierra guatemalteca y en la corporalidad indígena-femenina. Es un símbolo de la penetración española, violencia simbólica asentada en

una forma de poder que se ejerce directamente sobre los cuerpos y como por arte de magia, al margen de cualquier coacción fisica: pero esta magia sólo opera apoyándose en unas disposiciones registradas, a la manera de unos resortes, en lo más profundo de los cuerpos (Bourdieu, 2000: 54).

Manuel de la Rosa, arquetipo de la dominación masculina colonial asume como regla general que si las mujeres dicen "no", están diciendo "sí"; a partir de esa realidad (su Realidad), comete el acto de violación: “¡cómo costaba con la Toya!, pero él insistía porque allí estaban sus ojos que contradecían. Sus ojos decían todas las veces sí" (66). Al decir de María Luisa Femenías, y enlazando el personaje de la abuela, ella es la Otra Exótica ${ }^{6}$.

Producto de la violación, Victoria, quien es una niña aún, queda embarazada y la bisabuela de Irene (Amparo) reclama ante el padre del hacendado una boda para su hija porque está en juego el

valor simbólico de las mujeres disponibles para el intercambio, es decir, de su reputación y especialmente de su castidad -constituida en medida fetichizada de la reputación masculina, y por tanto del capital simbólico de todo el linaje-(Bourdieu, 2000: 63).

Esta acción será repetida, a su vez, por la abuela Victoria con la tía Ibis más adelante. Manuel de la

6. 
Rosa, a instancias de su padre, primero, y luego por deseo propio, después acepta casarse con Victoria quien dispone no hacerlo. Tanto la abuela Victoria, como la madre Nena, la tía Ibis e Irene son víctimas de la

violencia amortiguada, insensible, e invisible para sus propias víctimas, que se ejerce esencialmente a través de los caminos puramente simbólicos de la comunicación y del conocimiento o, más exactamente, del desconocimiento, del reconocimiento o, en último término, del sentimiento (Bourdieu, 2000: 12).

En la abuela Victoria la violación sexual es ejemplo del dominio masculino en una dinámica patriarcal que no acepta un "no" como respuesta; en Nena es el abandono y desatención de sus hijos por parte de padres ausentes, en Ibis es el desamparo y luego la imposición por una mujer (su madre) de un lazo forzoso que tiene que romper por violencia doméstica. Finalmente, en Irene es la huída de la casa por la irrupción de un "otro masculino colonizador" y su obediencia a normas sociales.

A pesar de los obstáculos y las penurias a las que se vio sometida la abuela Victoria, consigue un empleo de maestra rural, se lleva a los niños y la bisabuela Amparo: "A ese lugar perdido se fueron la señorita y sus hijos. Una mujer sola, con hijos, tan pobres, tan sucios, tan enfermos como sus propios alumnos analfabetos" (73).
Frente a una modernidad industrial que llega a Guatemala y que pretendía la prosperidad para los habitantes, se hallan personajes como Victoria y un sinnúmero de ciudadanos que no son integrados por el proceso modernizador. Por lo anterior, la abuela de la protagonista rompe esquemas y asume por sí misma una labor dura, ajena a los campos y la vida de los trabajadores campesinos, porque a pesar de todo "Guatemala era, toda, una gran finca de café" (62).

Scott Lash indica que con la asunción de la modernidad las relaciones de poder se mantienen o toman giros tendientes a acentuar ese dominio en relaciones de producción: "El poder Moderno, por su parte, actúa positivamente. Individualiza, normativiza y moviliza (mediante la inclusión en la ciudadanía) cuerpos en función de los intereses -económicos, militares, demográficos- de reproducción de lo social" (Lash, 1997: 175).

Del mismo modo, la sujeción no solo se manifiesta en asuntos de género como la abuela de Irene al terrateniente, sino que la mano de obra pobre, analfabeta y dependiente del poderoso perpetúa un colonialismo que ahora se asienta en los avances tecnológicos que solo consiguen más sujeción: "Y luego, brazos, más brazos, baratos y dóciles. Gente que recibiera conforme su mínimo jornal cada semana, en medallones impresos en las propias fincas" (62). Aunque la nación guatemalteca participe de 
la Modernidad, las relaciones de poder, de opresión y de sujeción son las mismas: colonizadores-colonizados, patrones-obreros, hombres-mujeres.

Así también para la abuela Victoria su suerte en el juego del dominio presentó un giro en el sentido de que eligió no casarse con el hijo del patrón; aunque su madre lo recomendara, escogió no quedarse en la finca perpetuando un dominio ancestral ahora reforzado por la modernidad $\mathrm{y}$, a cambio, decidió echar su suerte a volar siendo maestra en lugares alejados.

La abuela se halla, simbólicamente, en la transformación de Guatemala de nación cafetalera a otro país moderno, con enclaves poscoloniales. Es la visión del centro/periferia que aún prevalece en Irene y que a través de su relato lleva a comparar Vancouver con Ciudad de Guatemala. Irónicamente, tanto viajar por el mundo, ser otra mujer diferente en los procesos de socialización en cuanto a las otras féminas de la familia, no le han valido de mucho pues, aunque no lo quiere, sigue anclada en una relación que la tiene como su abuela Victoria detenida en el tiempo.

La nación, como las mujeres de la novela, representa la usurpación de espacios y la violencia de la explotación porque es colonizada en nombre de un progreso que se queda en las altas esferas y que cierra puertas a las clases subordinadas en la dinámica del capitalismo. Irene está en medio de ello y con sus juicios de valor integra una apreciación negativa para ambas naciones: Guatemala (por su fealdad) y Canadá (por su ruptura amorosa con su pareja):

"Entre patriarcado e imperialismo, constitución del sujeto y formación del objeto, desaparece la figura de la mujer, no dentro de una nada prístina, sino dentro de un violento ir y venir que es la figuración desplazada de la "mujer del tercer mundo" atrapada entre la tradición y la modernización" (Spivak, s.a.: 62).

Anteriormente se visualizaron espacios en la estructura de la obra ConPasión Absoluta a los cuales Irene se presenta. Recapitulando, llega a su casa materna, al pasado poscolonial a través de las historias relatadas por su abuela una y otra vez.

Más adelante se verá cómo Irene construye su nación a partir de lo que su abuela dice y a partir de lo que ella misma visualiza. Esta construcción compleja hecha de materiales diversos es una suerte de "ires y venires" de las mujeres que desde generaciones anteriores construyen piezas en un mosaico mucho más complejo que es la nación guatemalteca. En realidad, es la reconstrucción de la memoria histórica de la familia de Irene frente o subsumida en procesos macros como los conflictos armados, los tratados de paz, la violencia en las calles, entre otros.

Irene viene a ser, al igual que las mujeres de la familia, un sujeto 
nómada; al igual que su bisabuela, su abuela, su madre y sus tías vaga por el mundo. Vagar de un lugar a otro es un proceso de doble sentido: es espacial y temporal, posibilitando un sentido de ubicuidad para la protagonista.

Por eso en la visión de Irene se capta que "su nación" (la del antes) ya no lo es. A cambio, ha dado paso a una fealdad aplastante, así como el paso de la "Modernidad" ha acabado con su noción de "patria mía": "Las calles de mi infancia desaparecieron sepultadas bajo estas otras, demasiado pequeñas para contener el caos que las abarrota. El polvo tiñe de sepia el ambiente pesado" (15).

Resulta valioso en la cita anterior, reconocer cómo el pasado ha sido aplastado por lo nuevo generando caos. Irene no esconde, ni oculta una valoración negativa, casi peyorativa, que le permite enjuiciar el panorama de la nación guatemalteca.

Como en una burbuja, así debió quedar flotando su imagen de la patria; sin embargo, ahora en el presente y con la palabra "fealdad" repetida a lo largo de la obra, asume el cambio. Han sido años de alejamiento, tanto espacial como afectivamente, con sujetos que pudieran dar cuenta de las modificaciones de Guatemala. Para la protagonista, los taxis destartalados, el precio dolarizado, las expresiones en inglés en los anuncios, las camionetas llenas de pasajeros, los borrachos en las calles, los colores fuertes en las ropas, los chorros de humo, los negocios multiplicados y la pobreza no han hecho sino encerrarla en el espacio del hogar como una forma de huirle a toda esa transculturación; siente que su patria ya no es suya.

Guatemala cuenta en las palabras de la abuela o en los recuerdos de ella misma, o cuenta como en los tiempos primigenios y estructurantes de la identidad guatemalteca. Inclusive su patria pervive en las amenazas de los regímenes político-militares que detentaron el poder y oprimieron a las masas campesinas e indígenas.

Igualmente, mujeres como las de la familia llevan en sus voces retazos de historias entretejidas en el momento presente, aunque como señala Luce Irigaray: "todos los regímenes sociales de la "Historia" funcionan sobre la base de la explotación de una "clase" de productores: las mujeres" (Irigaray, 1982: 163-164).

Los regímenes político-militares dividen en dos la noción de patria que posee Irene. En ejes temporales detenidos quedaron su infancia y los juegos, así como los sujetos (Beatriz, Catalina y su hermano). La suerte que les tocó correr fue la de estar encerrados en las casas a causa de los bombardeos:

Dejé de visitar a las niñas antes de que terminaran las vacaciones. Los aviones daban vueltas en el cielo. La radio anunció el estado de sitio. Habia caído otro gobierno. No me dejaban salir de la casa y los días se estancaban (p. 31). 
Al mismo tiempo que se (re) elabora la historia de la nación guatemalteca en relatos/retazos de los testimonios orales de la abuela, se construye también la subjetividad de Irene porque la figura de la abuela materna ha sido preponderante en la constitución de la independencia y la sujeción que pueden manifestarse a un mismo tiempo en ella. $\mathrm{Al}$ respecto señala Rosi Braidotti:

la adquisición de la subjetividad es un proceso de prácticas materiales (institucionales) y discursivas (simbólicas), cuyo objetivo es tanto positivo -porque el proceso da lugar a prácticas de empoderamientocomo regulador -porque las formas de empoderamiento son el sitio de limitaciones y disciplinamiento (Braidotti, 2000: 183).

Por lo anterior, ConPasión Absoluta hace visibles y audibles a través de la enunciación de la protagonista las corporalidades y las voces de las mujeres de la familia perdidas en el sistema patriarcal que teje la Historia como procesos excluyentes, inacabados e incompletos. Irene es el sujeto estructurante, es el punto medio, el eje que integra Guatemala con Canadá, el tiempo pretérito de una colonialidad con la poscolonialidad que ahora se vive, el pasado con el presente y así, en múltiples construcciones simbólicas que llevan a concebirla como personaje que amalgama relaciones deícticas o que rompe con ellas.
En su análisis de la obra, Valeria Grinberg indica que Irene tiene un legado a cuestas y que debe ser preciso desatarlo o al menos liberarse de él ya que la protagonista "al inscribir las voces de las mujeres de la familia en el relato de su propia historia (...) se autorrepresenta como miembro de un grupo de mujeres, es decir como un sujeto anclado en una colectividad de género" (Grinberg, 2008).

Más que anclada en una colectividad de género, Irene representa el entrecruzamiento de ejes espaciales y temporales. De ahí su crisis de sentido y de arraigo a un ser humano o a un espacio definido. Posiblemente, el temor, la soledad y su constitución como sujeto simbólico producto de rupturas sociales, culturales y políticas dificulten ese proceso. Irene es un sujeto limítrofe:

Producto de una doble inscripción, como subalterno y como híbrido, el sujeto postcolonial surgirá -según Bhabha- en un intersticio (inbetween) y será capaz de negociar, invertir, desplazar y apropiarse de las estructuras de dominio que lo someten, produciendo otros lugares matriciales de experiencia de lo marginal-periférico (Femenías, 2005: 158).

Solamente en la compañía de la abuela halla consuelo para sus males, y aún después de la adultez, la protagonista siente en el regazo caluroso de la anciana un amor maternal: 
En las noches en que se sentía alentada se levantaba a arroparme y yo me dejaba cubrir por sus manos, sintiendo que esas sábanas que acomodaba amorosamente no reposaban sobre mi cuerpo, sino sobre mis heridas, sobre mi vida desarmada, sobre todo lo que nunca logré poner en orden... (54).

Igualmente, con la oralidad representada por la abuela, pues es ella quien introduce a Irene-niña y a Ireneadulta a múltiples relatos (históricos, tanto colectivos como individuales), se teje la subjetividad de la protagonista. A pesar de la gravedad de la anciana, en el proceso de transición de la vida a la muerte, narra - de nuevo- historias personales como una forma de reavivar recuerdos perdidos en los años de alejamiento abuela-nieta y en los espacios geográficos Guatemala-Canadá.

En otras palabras, en la formación del propio Yo de Irene se coló mucho de la abuela, poco de la madre: "Ya no sé si es su voz, o es la mía, que quiere recomponer aquellos relatos de entonces. Ella me formó el mundo. Pero ¿no viví yo en otro mundo? ${ }^{7} "$ (60).

Por otro lado, el manejo del eje temporal en el relato es complejo porque estructura, al igual que el espacio, múltiples perspectivas que no se detienen en un instante preciso. La protagonista juega con el aspecto cronológico develando, así, una maraña de acontecimientos que entrecruzan lo que ya vivió, con lo que experimenta y con lo que desea que se manifieste.

Ahora que llegó (don Asunción), su presencia transforma la casa y la atmósfera se vuelve densa. A mí me pasa como entonces: tengo ganas de irme. Quizá por eso me casé, proyecto fallido que, de antemano sabía, terminaría en ruptura. Sólo para irme de una vez por todas (25-26).

En el ejemplo anterior confluyen verbos que son modificados de un pasado a un presente inmediato. La sensación de incomodidad ante la presencia de don Asunción recuerda la misma sensación de fracaso matrimonial: diferentes en el momento acontecido, pero semejantes en el presente como experiencias frustrantes. Por lo anterior, apenas Irene entra al hogar materno dice: "El reino benigno de las mujeres es la cocina" (23) y se queja de las extenuantes horas de oficio doméstico que han hecho las sirvientas y las mujeres de su familia. Ella espera en la cocina a que llegue su madre y su abuela.

Ahora, Irene observa con ironía cómo se han dividido las funciones a lo interno del hogar. Su madre dispone, mientras que otras mujeres -al igual que lo hizo ella anteriormente-

7. El subbrayado es mío. 
hacen las labores domésticas perpetuando así el orden social instituido por el patriarcado, concebido como "preformativo puesto que es el efecto de un régimen que regula las diferencias de género. En dicho régimen los géneros se dividen y se jerarquizan de forma coercitiva" (Butler, 2002: 64).

Del mismo modo, apropiarse -al regreso- de espacios como la cocina, la cama al lado de su abuela, la calle, el barrio y (re)visitar sitios de juegos infantiles le permitirán a Irene evocar más recuerdos. Uno de ellos era el que compartía con sus amigas de la infancia y que consistía en subirse al escenario de la escuela, momento del pasado que lo relaciona con lo que ella llama "el juego del amor":

Los años pasaron, la huella quedó: siempre colocaría el amor en un escenario, envuelto en la intriga y el dramatismo del maquillaje y los ropajes que visten para el amor. Una escena aparte que, para abrirse, precisaba la indefinición y levedad de la sinuosa cortina. Un paso en falso, un sendero cuyo misterio podía transitarse sólo bajo el amparo del equivoco, de lo fantástico, del travestismo. (¿Será entonces que empecé a amarte?) (30).

Por consiguiente, en las reminiscencias de Irene confluyen desde un espacio presente y real otro espacio alejado en el tiempo: cuando está en Guatemala piensa en Vancouver, en Buenos Aires, en Mar del Plata porque los lugares recordados vienen acompañados de personas: "No quería olvidarla porque no quería olvidarte. Porque aún me dueles en el recuerdo, en el silencio que mantienes, en el silencio que mantenemos" (43).

Dos actos resultan difíciles para Irene como adicciones que hay que desechar: el cigarrillo y C: "Recorrí ese camino con mi mente mientras encendía un cigarrillo, el cuarto de la jornada, a pesar de que me proponía otra vez dejar de fumar" (44). No supera la relación frustrada de pareja, así como el engaño del triángulo amoroso. En realidad, la protagonista está sumida en una dominación ilusoria pero que ha echado raíces en su personalidad. Irene producto del mestizaje, mujer del Tercer mundo, está viviendo una relación amorosa con un hombre casado llamado Costa. Este sujeto es cosmopolita, y al igual que los antepasados, es el símbolo tradicional del colonialismo; en realidad, Irene vive otra dominación tan dolorosa o más que la que vivió su abuela y luego su madre. Desprenderse de esos lazos es romper con el sistema imperante.

El distanciamiento de la pareja ya se había hecho evidente en otros espacios diferentes a Guatemala y se reforzó con la imagen de la otra mujer pues $\mathrm{C}$ mantenía un vínculo que no había sido roto para iniciar la relación con Irene: "Los dos comprendimos en silencio que nos arrastraba 
también a su tumba. Agonizamos, morimos, los tres" (49).

El anonimato de la pareja de Irene se mantiene a lo largo de la obra con la letra C. Los pasajes a los que alude sobre su vida de pareja se destacan en letra cursiva en el texto original para indicar que corresponden a momentos distintos en el proceso de narración y hondamente cargados de nostalgia, rabia y distanciamiento.

Sin embargo, Irene indica que fue un acto de salvación encontrar a $\mathrm{C}$, aunque contradictoriamente tenga que perderlo luego, es una frustración latente y una sensación de pérdida que aún no ha podido aliviar: "Si algún día no fui la que soñaste, si algún día no fui quien soñé -mi vida tocó la tuya con miedo, queriendo salvarse-lo pagué con perderte, con estas ganas de vos que encaminan obsesivamente sus dedos para tocarte...)" (50).

Irene ha interiorizado a pesar de su educación, de su mundo y de sus vivencias, concepciones entronizadas de un patriarcalismo difícil de romper; tal vez por eso regresó a su puerto a ver pasar las embarcaciones:

Los hombres precisan navegar... el recuerdo de tu voz llega de siglos atrás y me alcanza. ¿Y las mujeres? A nosotras se nos enseña temprano la importancia de encontrar un puerto donde anclar nuestra nave. Un lugar seguro. La mujer espera. Cose y canta, dice la mitología (52).

Quizá, muy en el fondo, Irene encuentra en el regazo de la abuela su lugar seguro, el hogar -lugar del que no debió haber salido, según la visión patriarcal-, mientras evoca a $\mathrm{C}$ como un viajero. Espera, no sabe qué. Cose lo que posiblemente le dé sentido a su vida: miles de retazos perdidos en las páginas de la oficialidad y del sistema, utilizando para ello hilos que le proporcionan sus familiares y que ella procura rehacer de su vida misma.

En su lugar seguro es rescatable el hermano, quien fallece joven y que ella "lo admiraba muda. Comprendí que nunca sería como mi hermano, rebelde y valiente. Capaz de cosas enormes como resistirse al cura, o caminar desde el Liceo Guatemala hasta la casa, sin miedo" (38). Este es el único personaje masculino que posee un sentido de valentía frente a las imágenes peyorativas de don Asunción, o de los otros hombres que irrumpen en la familia.

Las conclusiones de este apartado indican que en la construcción de las identidades de las mujeres de la obra, específicamente en la identidad de género, se han inmiscuido el dominio y la violencia simbólica y real. Acceder a los cuerpos de las protagonistas, ha sido para la mayoría masculina, actos de violación poscolonial y rompimiento de subjetividades.

Por eso la abuela Victoria, Nena e Ibis, entraron forzosamente al dominio corporal por parte de los hombres con embarazos no deseados, mientras que Irene, no tanto corporal, 
pero sí emocionalmente, permanece atada a una relación de pareja fallida, rechazando al mismo tiempo al padrastro y extrañando a su hermano. Las mujeres fueron forzadas a introducirse en la dinámica y solo algunas de ellas lograron salir.

La relación de Irene con su madre fue dejada de lado para dar paso a un lazo afectivo, emocional e intersubjetivo muy fuerte con su abuela. En la anciana hallamos que la oralidad -como rasgo mítico femenino- deviene en historia personal entretejida con la Historia oficial y que le permitió a la protagonista crearse una visión de mundo que integraba a un mismo tiempo independencia y sujeción. Prevalecen por sobre la dominación patriarcal, la lucha y el esfuerzo de las mujeres como ejemplos por seguir.

Por lo anterior, a la par de la historia oficial que subsume a los sujetos no historizables, están las mujeres de la familia de Irene como sujetos fundantes de la noción de patria y de los acontecimientos ausentes en los documentos. Hablar hoy permite reelaborar "otra historia" tan poderosa como la que se ha erigido con base en el acallamiento de las voces femeninas.

\section{Canadá-Guatemala: el presente-futuro}

La oscilación de Irene -motivo de estudio en este apartado- permite reconocer que su vida se teje en discontinuidades que confunden, aparentemente, incluso su identidad. Ella es un sujeto que tiene la capacidad y así lo ha elegido, de situarse en los ejes espacio-temporales. Además, con su relato viene a integrar en un mismo momento cronológico, otros lugares y otros sujetos que pueblan su visión de mundo.

Guatemala y el pasado-presente, Canadá y otros lugares del continente americano, muestran también un pasado que pretende ser revivido en un futuro que quizá no se materialice: "Había olvidado esta lluvia en otra lluvia. Finita, delgada, perpetua (...) La lluvia en Vancouver mantiene las calles mojadas y brillantes. Parece que un espejo se plantara enfrente haciéndonos mirar sólo para adentro" (41).

Ese mirar para adentro se materializa en Guatemala, sitio que le permite rememorar y añorar otros parajes en su constante movimiento y que llevará a Irene, efectivamente, a confrontarse consigo misma en una visión identitaria. Judith Butler -citada por María Luisa Femenías- menciona que

los discursos identitarios de etnia $y$ de género se conforman según el ideal normativo a priori que supone la identidad (...) la continuidad, la coherencia en el tiempo, la autoidentidad, el género o la etnia atributos analíticos de la persona (...) que se producen y sostienen gracias a prácticas regulatorias (Femenías, 2005: 186). 
A lo largo de la obra, Irene se desdibuja en memorias, áreas y momentos hasta que cae en la cuenta de que ahora, desde las raíces de su patria, debe dar razón de quién es, de qué quiere y por qué ha regresado a sus orígenes. Afincarse en un espacio/tiempo le permitirá sanarse de sus heridas.

Por eso, para Irene, elementos resultantes simbólicos de la nación guatemalteca en el presente explican un forzoso reconocimiento. La realidad de su ciudad y el acceso a ella es un paso importante en el auto-reconocimiento de sí misma:

"Hay algo aqui que no arribo, que no arribaré nunca a comprender... excepto en ese milimétrico instante en que una zambullida en el lago Atitlán me arroje inesperadamente en los brazos de otra realidad y quede enmudecida, ensimismada" (13).

$\mathrm{Su}$ contraparte viene marcada por la idea que se ha forjado Irene de las ciudades visitadas. Ella quisiera ser atraída por las ciudades mismas, como si éstas cobraran vida y la envolvieran en la ensoñación de ser necesaria para las urbes:

A medida que pasaban los días, fui sintiendo la fuerza de la ciudad. Me fue alcanzando un imposible deseo: no marcharme nunca. Quería que ella sintiera lo mismo, que no me dejara ir, o en último caso, si la despedida fuese inevitable, que su presencia no fuese sólo un recuerdo mío.
Quería pensar que era posible dejar en ella huella de mi paso, deseo sin duda pretencioso: Buenos Aires habia tenido ya tantos amantes (222).

Atrás tienen que quedar los recuerdos y los deseos de continuar su vida de viaje y de diversión. Ahora, en su tierra natal, el llamado a un trabajo, a poner los pies sobre la tierra y asumir una serie de responsabilidades es obligatorio:

Necesitaba el empleo. Pero no terminaba de ajustarme a la idea de establecerme de nuevo en Guatemala... Fantaseaba con tomar un avión e irme sin destino fijo. ¿Regresar a Vancouver? El pensamiento reptaba de nuevo. Su movimiento imperceptible me asaltaba cuando ya era demasiado tarde para salir ilesa (80).

En la cita anterior, así como en la siguiente, se vislumbra una enorme contradicción. Irene desde su tierra natal sueña con Vancouver, al mismo tiempo que rechaza la idea de volver a la nación canadiense. Guatemala es el espacio anclado en la poscolonialidad, símbolo de trabajo forzado por la necesidad del dinero, aunque contradictoriamente es el rompimiento de ataduras con la pareja y consigo misma en el plano íntimo.

Canadá es la satisfacción de los sentidos (ofrece espacios de liberación como los bares, las amistades y una sensación de libertad), así como satisfacción y sujeción emocional. Ciudades como Mar Del Plata, 
Buenos Aires y Vancouver, primordialmente, le traen a la mente escenas relacionadas con su vida errante de pareja. $\mathrm{C}$ se halla en ellas y debe rechazarlas como una forma de liberarse del peso de los recuerdos:

A cualquier sitio menos allá. Estaba vivo en mi piel, su memoria era el mar en que sumergía mi cabeza para encontrar oxígeno. Sabía con claridad que no podía volver. Mi partida había sido un viaje sin posibilidad de retorno. La puerta estaba sellada (80).

La protagonista crea su propio texto cargado de significados en el que confluyen una serie de elementos: inicialmente, las otras ciudades ajenas a Guatemala se le presentan como el cambio frente a una colonialidad que se quedó estancada, es la satisfacción de sus sentidos frente a la imposición de normas y pautas sociales marcadas por su madre, y finalmente es la discontinuidad frente a un sistema de vida que le resultaba agobiante.

Ella habla, siente y piensa desde los espacios colonizados que añora pero que también le repelen en una asociación con la figura masculina amada; al respecto indica María Luisa Femenías que el subalterno habla colonizadamente, así Irene desea y rechaza los espacios desde una complejidad ambigua que se asienta en el rechazo y la aspiración: “... lo subalterno (en tanto que posición de subalternidad) ni tiene historia, ni cultura, ni significaciones propias. En sentido estricto no puede hablar sino colonizadamente, con la voz de las significaciones hegemónicas" (Femenías, 2005: 161):

En Commercial Drive, el Club Havana es uno de los lugares más concurridos (...) Sitio de encuentros de chilenos allendistas, salvadoreños efemelenistas, guatemaltecos ex guerrilleros, y recientemente, colombianos que huyen ya de otra forma de violencia, más adentrada en la posmodernidad, que mantiene al subcontinente latinoamericano infestado de mafias (85-86).

Irene, al igual que su abuela Victoria, es nómada y no se detiene en su andar más que para curar heridas u olvidar. Así como la anciana abandonó la comunidad para romper lazos con el dominador en búsqueda de mejores oportunidades, así también la nieta busca, pero no sabe qué. Indica David Lyon:

"Los lazos tradicionales de la familia, el linaje y la comunidad, rotos por la nueva movilidady la inexistencia de una regulación convencional, sólo fueron sustituidos por la incertidumbre, la pérdida de dirección y la sensación de soledad de cada individuo" (Lyon, 1996: 62-63).

En el espacio familiar, Irene por fin se da cuenta de que su vida carece de sentido y que aunque su familia esté presente, busque un trabajo, se integre al caos de la ciudad guatemalteca y comparta con amistades, son vacíos difíciles de llenar. Sólo un 
proceso de auto-sanación permitirá darle un norte a su vida.

Una clara y definida visión especular le permite a Irene adentrarse en sí misma y desdoblarse. Al verse en los ojos del recuerdo lo hace en el pasado como ente constructor de esas acciones y como testigo de ellas:

Me veo con los ojos del recuerdo. Mis pasos recorren otra vez el camino de regreso: soy testigo de mí misma. Estoy presente en ese momento al que escojo llamar "entonces". Y porque estoy "presente" deja de ser pasado. ¿Qué juego es este? (14).

La felicidad asociada al pasado, a los juegos infantiles y las despreocupaciones de ser adolescente se le muestran en ese presente que es dejado como pasado: "Entonces la felicidad era fácil y no una incierta tierra prometida" (19).

Hay dos acciones que molestan a Irene: la vuelta a su país y a su casa: "He recorrido un círculo perfecto: salir de esta casa, de este país, para regresar a este país, a esta casa, feudo tenebroso de Don Asunción" (21). Dicho círculo es, efectivamente, la estructura narrativa presente en la novela, circularidad en toda circunstancia y momento; al respecto indica Hélene Cixous que

todo escritor, todo artista, se ve algún día impulsado a asomarse al génesis de su propio "ser-artista", esa rareza fatal. Es el texto supremo, el que se escribe volviéndose para regresar al lugar donde se juega para ganar o para perder la vida (Cixous, 2001: 172).

Y esa circularidad hace que Irene retorne a Guatemala volviéndose en piezas, no como un todo. Su identificación como mujer del presente se construye sobre la base de múltiples retazos, algunos dejados aquí y allá. También Irene se estructura a través de lo que ve en los demás, como en este siguiente ejemplo:

No, no quería regresar, y estoy aquí hace un año, cansada como si recién hubiese regresado de un largo viaje, llena de polvo del camino (...) Ya nadie me siente de aqui, y yo sólo a veces, como ahora, sentada en medio de la noche (...), en este momento, me siento de aquí (39).

La transición es un rasgo que definiría la identidad de Irene, porque al igual que señala Jurgen Habermas, Irene integraría la conciencia, el accionar de un mundo de vida en el que lo moderno "expresó una y otra vez la conciencia de una época que se mira a sí misma en relación con el pasado, considerándose resultado de una transición desde lo viejo hacia lo nuevo" (Habermas, 1989: 131). De ahí esa dinámica constante de la protagonista para percibirse, aunque no lo quiera o desee, desde "el ahora, el aquí". Irene piensa en su futuro con temor: "Pero este volcarse hacia delante, esta 
anticipación de un futuro indefinible y ese culto de lo nuevo, significan, en realidad, la exaltación del presente" (Habermas, 1989: 132).

Ella se autoanaliza con sentimientos de indefinición: "Lo cierto del caso es que me encontraba perdida en el ancho y largo limbo" (54). Esa sensación de desdibujamiento la acompañará a lo largo de la obra y en el tiempo cronológico que inicia con su llegada a Guatemala y la muerte de su abuela. Hasta que la anciana fallece se opera un cambio en Irene quien considera lo siguiente: "Mi vida está suspendida. Con exasperación me percato de que no tengo voluntad para reinventar mi propia historia. El pasado abre su enorme boca, me traga. Quise borrarlo y, ahora comprendo, me miraba de regreso con su intangible reflejo" (69).

Finalmente, con las primeras cartas que escribe a $\mathrm{C}$, reconoce que se define en la labor de escritura-tejido: "Ese día te escribí una nota: me hiciste sentir hoy que mi nombre, mi cara, mi historia tienen aquí un lugar y un sentido" (45). Irene encuentra en ello un norte, escribir es acaso exteriorizar lo que por tanto tiempo le ha atormentado y, en consecuencia, ella necesita autoafirmarse en su ex pareja, aunque se encuentre ausente y en los instantes vividos con él. Como acto de rememorar afianza su yo:

El rechazo, la exclusión, de un imaginario femenino pone, por cierto, a la mujer en posición de experimentarse a sí misma sólo fragmentariamente, dentro de los márgenes poco estructurados de una ideología dominante, como residuos, o excesos de un espejo investido por el "sujeto" (masculino) para reflejarse él, para duplicarse a sí mismo en él (Irigaray, 1982: 29).

En piezas, Irene se (re)construye y (re)construye a las mujeres de su familia: "(Re)encontrarse, para una mujer, solamente podría significar entonces la posibilidad de no sacrificar ninguno de sus placeres a otro, de no identificarse con ninguno en particular, de no ser jamás simplemente una" (Irigaray, 1982: 29). Es Irene experimentado la satisfacción de sus sentidos en las grandes ciudades, la que escribe y se desahoga, la que despierta a la realidad en la ciudad guatemalteca. Del mismo modo, es aquella persona que reacciona forzosamente con la muerte de su abuela Victoria. Son varias Irenes fragmentadas a un mismo tiempo, separadas y unidas de nuevo para definirla como sujeto. Esa pluralidad de fragmentos da sentido a su vida.

Lo analizado aquí me permite señalar que Irene necesita de los otros, las otras, de las mujeres de la familia quienes, en conjunto, contribuyen a cerrar parte de su identidad. Sin embargo, es consciente que lo anterior se logra si también se mira por dentro y encuentra asideros a los que aferrarse para completarse como un todo. Son importantes las menciones de los 
espacios, pues asociados a ellos están las experiencias de vida que la han marcado en el devenir como mujer.

Asimismo, desde su ciudad natal ha llegado a completar el ciclo de su existencia en el sentido de que reconoce su mundo de vida como algo sumamente complejo cargado de viajes, idas y venidas, situaciones individuales o colectivas que fueron posibles sólo desde su afán de quererse explicar y encontrar una razón de ser.

\section{Conclusiones}

En la obra ConPasión Absoluta de Carol Zardetto se reconoce que en la construcción de la nación guatemalteca se hallan mujeres inmersas en un dominio patriarcal afianzado por siglos, latente aún en las sociedades, y que se manifiesta en todos los ámbitos.

Por eso, Irene en el círculo del hogar se construye como hija pero no de su madre, sino de su abuela. La llegada de "otro padre" ha destruido un lazo que posiblemente se hubiera mantenido de no ser por el casamiento de Nena con don Asunción. Es con su abuela Victoria con quien Irene teje hilos cargados de cotidianidad (relatos, cocina, juegos, vivencias, experiencias y de más) que la mantienen enlazada a su Patria-Madre porque es su Abuela-Patria.

Como dijo Irene, con la abuela Victoria se formó el mundo, su mundo cargado de subjetividad, de oralidad y de enseñanzas en un espacio que como una pompa de jabón se destruyó por el sistema patriarcal, las luchas políticas de la nación, y en el presente, por la enfermedad de la anciana y siempre por el dominio poscolonial.

Paralelas a las vivencias personales de la protagonista con los hombres, se encuentran las de las mujeres de su familia. Es lamentable que la base de esas relaciones sea el dominio masculino y el consecuente, siguiendo a Pierre Bourdieu, uso y abuso de las protagonistas como objetos de intercambio. Así, entonces, se reconoce que la violencia simbólica deviene en sujeción, tanto corporal como de lazos afectivos, que no le permiten, por ejemplo, a Irene desembarazarse de su adictiva unión con $\mathrm{C}$ hasta que escriba sobre ella.

Relacionado con lo anterior, se entrecruzan, entonces, uniones de pareja con la visión de patria. Esto por cuanto las mujeres, como personajes, son apéndices de una historia que se ha escrito desde el centro, que las ha marginado en la construcción de sus naciones y que las ha desechado con invisibilizarlas y acallarlas. Irene, como cronista, habla y escribe en un presente que se construye desde un pasado, para vislumbrar un futuro (¿quizás diferente a lo ya vivido?).

(Re)encontrarse, (re)construirse y (re)experimentar para Irene son actos decisivos ahora. Siguiendo a Luce Irigaray, si la protagonista es 
"una sola" se distribuye como miles de partículas, por eso en las muchas Irenes confluyen una, todas. Su proceso de mediación le permite escindirse en espacios, en tiempos y en circunstancias. Irene es oscilación, es errancia. Sin embargo, también debe asumirse desde los otros para contribuir con su proceso de identificación aquí y ahora.

El fluir espacial-temporal, como una visión eminentemente dialéctica y deíctica, le permite al personaje femenino reconocer a Guatemala como la periferia subestimada siempre. Esa periferia cobra sentido hasta que ella no salga de la situación de desdibujamiento y escriba desde su subjetividad. Canadá y los otros espacios solo han venido a afianzar lo que creía perdido por el sistema o por la cotidianidad de la nación guatemalteca.

La protagonista es la encargada de resignificar su pasado y el de sus familiares femeninas desde la marginalidad de etnia, género y clase social y puede lograrlo con un llamado de autonomía y autodeterminación que solo es posible conjugando en tres actos subestimados en las mujeres "sus demonios internos". Evocar, enunciar y escribir son, hoy por hoy, actos identificatorios estructurantes de su personalidad.

\section{Referencias}

Benjamin, J. (1997). Sujetos iguales, objetos de amor. Ensayos sobre el reconocimiento y la diferencia sexual. Buenos Aires: Paidós.
Bhabha, H. (1997). "The World and the home". En McClintck, Anne, Mufty, Aamir y Shohat, Ella (compiladoras). Dangerous liaisons. Gender, Nation and Postcolonial Perspectives. (pp. 445-455). Minneapolis: The University of Minnesota Press.

Bourdieu, P. (2000). La dominación masculina. Barcelona: Anagrama.

Braidotti, R. (2000). Sujetos nómades. Corporización y diferencia sexual en la teoría feminista contemporánea. Buenos Aires: Paidós.

Burín, M. (1992). "Familia y subjetividad femenina: la madre y su hija adolescente". En Gilberti, Eva y Fernández, Ana María (compiladoras). La mujer y la violencia invisible. (pp. 215-228). Buenos Aires: Editorial Sudamericana.

Butler, J. (2002). "Críticamente subversiva". En Rafael Mérida Jiménez (ed.). Sexualidades transgresoras. Una antología de estudios queer. (pp. 55-79). Barcelona: Icaria Editorial, S. A.

Cixous, H. (2001). "La hora de Clarece Lispector". En Cixous, Hélene. La risa de la medusa. Ensayos sobre la escritura. (pp. 155-199). Barcelona: Anthropos.

Correa, H.D. (1987). "El miedo al Otro. Violencia, política y deseo en Colombia". Magazín dominical. N. 11, septiembreoctubre. pp.: 19-21.

Femenías, M. L. (2005). "El feminismo postcolonial y sus límites”. En Amorós, Celia y de Miguel, Ana. Teoría feminista: de la Ilustración a la globalización. (pp. 153213). Madrid: Minerva.

Giddens, A. (1993). Consecuencias de la Modernidad. Madrid: Alianza Editorial.

Grinberg Pla, V. (2008). "Recordar y escribir para vivir. La recuperación (inter)subjetiva del pasado en El corazón del silencio de 
Tatiana Lobo y ConPasión Absoluta de Carol Zardetto". Istmo. Revista Virtual de estudios literarios y culturales centroamericanos. No 16, enero-junio.

Habermas, J. (1989). "Modernidad: un proyecto incompleto". En Nicolás Casullo (ed.). El debate Modernidad-Posmodernidad. (pp. 131-144). Buenos Aires: Editorial Punto Sur.

Irigaray, L. (1982). Ese sexo que no es uno. Madrid: Saltés.

Lash, S. (1997). Sociología del posmodernismo. Buenos Aires: Amorrortu Editores.

Lyon, D. (1996). Postmodernidad. Madrid. Alianza Editorial.
Quijano, A. (2000). “Colonialidad del poder, eurocentrismo y América Latina". En: Lander, E. (Compilador). La colonialidad del saber: eurocentrismo y ciencias sociales. Buenos Aires: CLACSO.

Spivack, G. (s.a.). ¿Puede hablar un subalterno? Traducción del Centro de Documentación sobre la Mujer. Buenos Aires: Centro de Documentación sobre la Mujer.

Zardetto, C. (2005). ConPasión Absoluta. Guatemala: F\&G Editores.

Zardetto, C. (2008). Conversatorio. Instalaciones del CIICLA (Universidad de Costa Rica), 5 de noviembre de 2008. 
